\title{
Dental Recall
}

National Cancer Institute

\section{Source}

National Cancer Institute. Dental Recall. NCI Thesaurus. Code C52573.

A routine dental appointment for a patient of record that includes diagnostic procedures and preventive care. 